surgeons are reluctant to stage the axilla during conservative surgery. Although adjuvant systemic treatment appears to be given to a fairly large proportion of patients, this is usually endocrine treatment. Chemotherapy is given less often, perhaps because of the difficulties in administering it in a general surgical clinic.

Finally, we were disappointed to find that so few patients were included in clinical trials-for example, only $37 \%$ of surgeons who treated more than half their patients with adjuvant systemic treatment did so as part of a clinical trial.

With the prevalence and diversity of breast cancer and the complexities of the many options for treatment perhaps the time has come to encourage treatment by specialised breast units. This would permit conformity of management of the disease and facilitate research into new modes of treatment throughout the country.

We thank the Breast Cancer Research Trust for supporting this survey,
Lynne Wilcox for collating the data, and Janice Davidson for supervising the computer documentation.

\section{References}

1 Veronesi U, Saccozzi R, Del Vecchio $\mathrm{M}$, et al. Comparing radical mastectomy with quadrantectomy, axillary dissection, and radiotherapy in patients with small cancers of the breast. $N$ Engl f Med 1981;305:6-1

2 Cancer Research Campaign. Management of early cancer of the breast. Report on an international multicentre trial supported by the Cancer Research Campaign. Br Med f 1976;: 1035-8.

3 Calle R, Pilleron JP, Schlienger P, Vilcoq JR. Conservative management of operable breast cancer. Cancer 1978;42:2045-53.

4 Pierquin B, Owen R, Maylin C, et al. Radical radiation therapy of breast cancer. Int $\mathcal{J}$ Radiat Oncol Biol Phys 1980;6:17-24.

5 Bonadonna G, Brusamolino E, Valagussa P, et al. Combination chemotherapy as an adjuvan treatment in operable breast cancer. $N$ Engl f Med 1976;294:405-10.

6 Baum M, Brinkley DM, Dossett JA, et al. Improved survival amongst patients treated with adjuvant tamoxifen after mastectomy for early breast cancer. Lancet 1983;ii:450.

Fisher B, Newman C, Brown A, et al. Treatment of primary breast cancer with chemotherapy and tamoxifen. N Engl f Med 1981;305:1-6.

(Accepted 6 March 1985

\title{
Validation of a self administered questionnaire to elicit gastrointestinal symptoms
}

\author{
E M CHISHOLM, F T DE DOMBAL, G R GILES
}

\begin{abstract}
Self administered questionnaires are becoming popular investigative tools in medical research, yet few reports state the extent of methods used to validate these questionnaires before their general use. A pilot study was therefore carried out to validate a 41 item questionnaire for use in a population screening study for gastrointestinal disease.

Participants in the study comprised 69 population controls, 40 patients with benign disease, and 35 patients with gastrointestinal cancer. Acceptability, ease of completion, reliability, and reproducibility of the questionnaire were all assessed. Only one subject refused to complete the questionnaire. Ninety six per cent of the questions were completed by each subject and only one response in $\mathbf{1 4 4 0}$ was altered in the reproducibility study. The questionnaire disclosed symptoms similar to those elicited by a clinician and highlighted unreported gastrointestinal symptoms in the control group. Three questions were found to be unreliable and were altered before the questionnaire was put into general use.

It is concluded that a pilot study to validate a new questionnaire is simple to perform and necessary to identify unreliable questions.
\end{abstract}

\section{Introduction}

Self adminstered health questionnaires have been used as an adjunct to medical history taking for many years, ${ }^{1}$ but more recently questionnaires have been seen as investigative tools to identify risk groups for cardiac disease,,$^{2}$ colorectal neoplasia, ${ }^{3+}$ and upper

University Department of Surgery, St James's University Hospital, Leeds LS9 7TF E M CHISHOLM, BSC, FRCS research fellow

F T DE DOMBAL, MD, FRCS, reader in clinical information sciences

G R GILES, MD, FRCS, professor of surgery

Correspondence to: Professor G R Giles. gastrointestinal disease. ${ }^{5}$ Few questionnaires, however, have been subjected to critical statistical analysis to determine their validity before being used clinically. ${ }^{6}$ To be valid a questionnaire needs to meet five criteria: $(a)$ to be acceptable to the population under study; (b) to be easily completed; $(c)$ to be consistent-that is, to elicit responses similar to those gained in a conventional doctor-patient interview; $(d)$ to be reproducible when administered on two separate occasions; $(e)$ to be of value or use when complete.

We report the steps taken to validate a questionnaire to elicit gastrointestinal symptoms in a screening programme for bowel cancer.

\section{Questionnaire}

The questionnaire contained 41 questions. Eighteen were specifically related to gastrointestinal symptoms - oesophagus (3), stomach (3), bowel habit (8), weight and appetite (4)-and the remainder covered epidemiological data (4), previous medical history (6), family history (2), and a general systems inquiry (11)-respiratory system, genitourinary system, and drug usage. The questions were closed in nature and it was possible to omit five responses if negative answers were given to the preceding question. To answer a question a tick was placed in the appropriate yes or no box.

\section{Patients and methods}

A total of 144 subjects were enrolled and were divided into three groups: 69 "normal" subjects who were not attending hospital; 40 patients with proved benign gastrointestinal conditions; and 35 patients with proved gastrointestinal cancer. All 144 subjects were required to complete the form unaided in order to assess the acceptability and feasibility of completing the questionnaire. A test-retest system was used to assess the reproducibility of the responses, 20 subjects being required to complete a second questionnaire after a two week interval.

Twenty three patients with symptoms referred to hospital by their general practitioner completed a questionnaire before being interviewed in the routine manner by a consultant. To determine the consistency of the responses on the patient's questionnaire the clinician then completed an identical questionnaire on the basis of the interview and without reference to the patient's form. The two forms were then compared using kappa statistics. 
Statistical method-Since the possibility of chance agreement between two series of replies to the same set of questions varies according to the incidence of positive and negative replies to the individual questions, the kappa statistic was calculated to adjust for the contribution of chance agreements. $\mathrm{Kappa}(\mathrm{k})$ is calculated according to the formula, $\mathrm{K}=(\mathrm{Po}-\mathrm{Pe}) /(1-\mathrm{Pe})$, where Po is the observed proportion of agreement and $\mathrm{Pe}$ is the proportion of expected agreement from chance and calculated from the marginals in a two by two table. The values for kappa vary from 1.0 where there is total agreement to -1 where there is total disagreement. A value of zero corresponds to chance agreement alone.

\section{Results}

Acceptability-One subject refused to complete the questionnaire.

Feasibility - Three subjects failed to complete the questionnaire owing to poor eyesight or dyslexia. The average time for completion was seven minutes (range four to 10 minutes). The completion rate for the questionnaire was $96 \%$ of all questions.

Reproducibility - In all three groups the test-retest study showed that only one answer was altered in one questionnaire, and this related to family history. Thus only one response was changed out of a possible 1440 answers.

Consistency - In the study which compared responses obtained on the questionnaire with those obtained by the consultant clinician kappa statistics were applied to the 18 gastrointestinal symptoms. In 15 questions there was a close correlation of answers and all the kappa values exceeded 0.85 . With three questions, however-namely, those designed to elicit responses concerning tenesmus, early satiety for food, and new episodes of abdominal pain-the kappa values were $0.2,0.125$, and 0.3 respectively. The remaining general questions all had kappa values of 1 .

Applicability - When the responses to the gastrointestinal questions were compared among the three groups of subjects the number of positive responses was naturally greater in the hospital referred groups. Of 65 subjects in the normal group, $54(83 \%)$ had zero or one positive response, seven having three or more positive responses. In the group with cancer 33 of $35(94 \%)$ had three or more positive responses, as did 33 of the 40 subjects $(83 \%)$ in the benign disease group (table). Follow up assessment of the seven

\begin{tabular}{|c|c|c|c|}
\hline $\begin{array}{l}\text { No of positive } \\
\text { responses }\end{array}$ & $\begin{array}{l}\text { Normal } \\
(n=65)\end{array}$ & $\begin{array}{l}\text { Benign } \\
(\mathrm{n}=\mathbf{4 0})\end{array}$ & $\begin{array}{l}\text { Cancer } \\
(\mathbf{n}=35)\end{array}$ \\
\hline 0 & 39 & 0 & 0 \\
\hline 1 & 15 & 3 & 0 \\
\hline 2 & 4 & 4 & 2 \\
\hline$\geqslant 3$ & 7 & 33 & 33 \\
\hline
\end{tabular}

"normal" patients showed that one had a confirmed diagnosis of ulcerative colitis, two were treated for dyspeptic symptoms on follow up, and three were referred for investigation of rectal bleeding and were found to have haemorrhoids. The remaining subject, who had right sided abdominal pain, loose altered stool, and altered urine colour, was found to have stones in the common bile duct on investigation.

\section{Discussion}

The format and content of the questionnaire were clearly acceptable to the population sampled. The high degree of compliance recorded, however, may have been biased by small sample size. Problems in completing the questionnaire would probably occur commonly if the questionnaire were applied to the population at large, owing to embarrassment, lack of reading glasses, and illiteracy.

The benefit of the realiability section of the pilot study was to identify those questions that were unreliable before general use. The phraseology of these questions was identical with that used in previous questionnaires and structured interviews, ${ }^{1358}$ and their apparent failure in our specific study reinforces the view put forward by Oppenheim that merely using questions from other questionnaires without testing them in the context of their eventual use cannot be justified. ${ }^{9}$
By using the test-retest assessments and the correlation study we were able to observe the ability of the questionnaire to elicit symptoms successfully both in the known symptomatic groups and also in the supposedly normal population group, leading to the detection of previously unsuspected gastrointestinal disease. Furthermore, and equally important in the screening setting, a negative response to gastrointestinal questions was found to be a true negative response in all 15 reliable questions, and on retesting no negative gastrointestinal response became positive. These findings are consistent with other data on reproducibility studies of health questionnaires. ${ }^{\circ 11}$

The questionnaire accurately elicited symptoms of gastrointestinal disease in the hospital group, and on subsequent follow up of the heavily symptomatic "normal" group further disease was identified, so the potential value of the questionnaire can be seen. This is shown in the table below where the distribution of positive responses is analysed by group. Here the risk of gastrointestinal disease and therefore the potential need for investigation can be defined. In the case of this particular questionnaire the risk is defined by three or more positive responses.

We conclude that a pilot study of any questionnaire is mandatory to identify any faults in its format or content; that it takes little time or effort to perform; that simply using questions from established health questionnaires does not imply reliability; and that statistical methods should be applied to the correlation studies to ensure the validity of the questionnaire.

By performing our pilot study we have devised a questionnaire that can reliably elicit symptoms of gastrointestinal disease consistent with the ability of a clinician but can also accurately identify people with established gastrointestinal disease and can highlight normal subjects with symptoms, as yet unreported to a doctor, that merit further investigation.

\section{References}

1 Brodman K, Erdmann AJ, Lorge I, Wolff $\mathrm{HG}$. The Cornell Medical Index, an adjunct to medical interview. JAMA 1948;140:530-4.

2 Rose G, McCartney P, Reid DD. Self-administration of a questionnaire on chest pain and intermittent claudication. Bntish fournal of Preventive and Social Medicine 1977;31:42-8.

3 Silman AJ, Michell P, Nicholls RJ, et al. Self-reported dark red bleeding as a marker comparable with occult blood testing in screening for large bowel neoplasms. Br I Surg 1983;70:721-4.

4 Farrands PA, Hardcastle JD. Colorectal screening by a self-completion questionnaire. (iut $1984 ; 25: 445-7$

5 Mann J, Holdstock G, Harman M, Machin D, Lochry CA. Scoring system to improve cost effectiveness of open access endoscopy. Br Med 7 1983;287:937-40.

6 Pecaroro RE, Inui TS, Chen MS, Plorde DK, Heller JL. Validity and reliability of a selfadministered health history questionnaire. Public Health Rep 1979;94:231-8.

7 Koran LM. The reliahility of clinical methods, data and judgements. N Engl I Med 1975;293:642. 6.

8 Gumpel JM, Mason AMS. Self-administered clinical questionnaire for outpatients. $\mathrm{Br}$ Med $\mathrm{f}$ 1974;ii:209-12.

9 Oppenheim AN. Questionnaire design and attitude measurements. London: Heinemann, 1978. 10 Collen MF, Cutler JL, Jiegelaub AB, Cella RL. Reliability of a self-administered medical questionnaire. Arch Intern Med 1969;123:664-71.

(Accepled 28 Februan 1985)

Can "crossed dominance" in a child-for example, natural use of left hand and right eye-cause difficulty in learning to read? Is it related to dyslexia?

In the Isle of Wight survey there did not appear to be any correlation between sinistrality or ambiguous laterality and poor reading achievement, but in most reports uncertain or crossed laterality is associated with a higher proportion of reading difficulties. ${ }^{1.3}$ This was particularly so in the early studies of word blindness and the keystone to the work of Orton in the 1920s. Some children can change laterality preference even up to puberty. Several theories have been suggested to explain the interconnection between dyslexia and ill lateralisation: $(a)$ a common difficulty with visuospatial tasks, $(b)$ both features are expressions of immaturity of cerebral maturation, or $(c)$ children who lack firm laterality preferences are more vulnerable to the effects of stress.-E M R CRITCHLEY, consultant neurologist, Preston.

1 Rutter M, Yule W. The Isle of Wight community survey. I Child Psychol Psychiaby 1975;16:181-97. 2 Zangwill $\mathrm{OL}$. Cerebral dominance and us relation to psychological function. Edinburgh: Oliver and Boyd, 1960.

3 Critchley M, Critchlev EA. Duslexia defined. London: Heinemann, 1978. 